respectively in 1486 and 1484 , seem to be only recorded in the Berlin Kommission's list of fifteenth-century broadsides.

Finally, mention may be made of two vernacular pieces of great interest and rarity :

760, H. Rosenblüt, Ein lieplich bistory, von grosser schone, gedult und keuscheyt einer edleln keyseryn, 4to, 8 leaves, printer unidentified, n.d.

884, Wunderzeichen unserer lieben Frauen zu Alt-Oetting, 4to, 4 leaves, perhaps printed by Peter Wagner at Nuremberg.

Dr.Ludwig gives facsimiles of pages of Proctor 99(Gratianus, Schoeffer, 1472, on vellum) showing a fine miniature; of Proctor 9337A (Brussels, Brothers of the Common Life); and of Hain 12031 (Augsburg, C. Schnaitter). His catalogue is a pleasure to all who are interested in this attractive branch of bibliography.

S. Gaselez.

\title{
THE NEW SHAKESPEARE 1
}

Sir Arthur Quiller-Couch and Mr. John Dover Wilson are assuredly the most alive and alert pair of editors who have ever applied their knowledge and imagination to produce a new annotated text of Shakespeare. It is thus not surprising that the first sample of their work in its attempt to quicken the enjoyment of the average Shakespeare-lover, and at the same time keep him in touch with the latest methods and results of scholarship is the most adventurous edition of The Tempest that has ever been published. It speaks well, however, for the success of their enterprise that they have been able to introduce so many new features with so little self-consciousness or elaboration.

The most daring of the new features is the introduction of new stage-directions, which enable readers to visualize the

1 Tbe Works of Sbakespeare. Edited for the Syndics of the Cambridge University Press by Sir Arthur Quiller-Conch and John Dover Wilson,-The Tempest. 
scenery and the byplay and moods of the characters as the editors with the aid of their united study and imagination themselves see them. To nine readers out of ten these new stage-directions will be really helpful; the tenth, when he first catches sight of them, may complain that they fetter his own imagination and criticize them as footnotes brought up into the text. Such a censor, however, if he keeps an open mind, will find that in practice his own imagination is stimulated rather than cramped, and if occasionally he is moved to substitute in his neatest hand a stage-direction of his own, will more often have the pleasure of finding ideas he cannot but approve skilfully expressed.

A change of a different kind is the reduction almost to vanishing point of the prominence of the division into acts and scenes which in most editions is so blatant. Shakespeare himself did not usually think dramatically in Acts, and the conventional divisions sometimes separate scenes which belong closely together. The change is clearly right. Thirdly, the punctuation of the text as originally printed in the Folio of 1623 is seriously reckoned with, and a very carefully worked out extension of our ordinary pointing has been devised so as to retain the Folio values wherever they are dramatic, without confusing readers used only to grammatical stops. This is done mainly by using four dots for a full stop and three for a colon where these denote dramatic pauses. The most intriguing return to the Folio, however, is a simple restoration. This comes in Ariel's account of the passengers abandoning the enchanted ship in their panic. As here printed it reads :

$$
\text { ‘. all but mariners }
$$

Plunged in the foaming brine, and quit the vessel; Then all afire with me the King's son, Ferdinand, With hair up-staring-then like reeds, not hairWas the first man that leaped ;'

$$
\text { E } 2
$$


In isolation this is convincing. But former editors who transferred the semicolon which follows 'vessel ' to the middle of the next line, after 'me', carried on the picture of Ariel 'flaming amazement' and burning ' in many places' all over the ship, and made the second 'then' balance the first very neatly. It is hard to decide which punctuation is better.

As regards the introduction of new readings into the text a self-denying caution has been observed. About a score of emendations by Dryden, Rowe, Theobald, Capell, Stevens, Johnson, Ritson, Staunton, Dyce, Aldis Wright, Nicholson, and Professor Moore Smith have been accepted. Wright's 'Earthës' for 'Earth's' in 'Earth's increase, foison, plenty' in the masque spoils a beautiful monosyllabic foot and introduces a needless archaism. Almost all the others are quite, or nearly, certain. ${ }^{1}$ As much may be said for all the four new readings we have noted in the text (II. i. 62, ' gloss, as' for 'glosses'; Iv. i. 9, 'boast hereof' for 'boast her of', where ' of' has been glossed as 'off'; Iv. i. I64, 'Come with a thought, I think thee, Ariel, Come,' for 'I thank thee'; and IV. i. 232, 'Let's all on And do the murder first' for 'Let's alone'). Three others seem equally good: 'having minted truth', for 'having into truth' in the famous crux in 1. ii. IOO, the picture of the man who by 'telling' his forged coins persuades himself that they are genuine being itself most apt and backed by a singularly close parallel; ' eked ' for 'deck't' in I. ii. I 55, and 'Sir' for ' I', in Ir. i. 93, for both of which we can only refer to the very ingenious notes. All these should surely be promoted to the text later on, and to have made seven good hits (against four or five

1 One more might have been added. P. A. Daniel contended in his Notes and Conjectural Emendations that the 'cry' which precedes 'Cockadiddledow' in Ariel's 'Come unto these yellow sands' was a stage-direction, and this seems good enough to be adopted in 2 second edition or at least mentioned in a note. 
less convincing ones) in a play on the whole so well printed and much edited as The Tempest is no small feat. Even if they were lucky 'shots', these emendations would prove much skill in the marksmen; but they are more than 'Shots', for each one is carefully worked out 'diplomatically', according to the way in which the reading printed in the Folio and the emendation proposed would be written in an 'English' hand of Shakespeare's day. Of this English hand a specimen is shown in a facsimile of some sixteen lines of the scene in the play of Sir Thomas More which Sir E. Maunde Thompson has given good reasons for believing to be in Shakespeare's autograph and which he has at least proved to be in the class of hand which Shakespeare wrote.

To have done as much as this would have been much, but the play as a whole as well as the words of the text is looked at with new eyes, which prove themselves extraordinarily keen in tracking out what their owner calls 'bibliographical clues'. In a preface to the notes, headed 'The copy used for The Tempest', evidence is brought together which makes it certain that the latest of Shakespeare's plays must have existed in a much earlier form, have been first rewritten and then abridged, and then once more adapted for a performance at Court. Still better : in a 'textual introduction' to the edition as a whole Mr. Wilson shows how these methods are of general application, and holds out to us a hope that, as each successive play is scrutinized in turn, the true nature of the 'First Folio' will at last be revealed.

And to all this Sir Arthur Quiller -Couch prefixes a fine introduction, full of wise things about Shakespeare admirably said; and Mr. Harold Child adds an excellent note on the stagehistory of $T$ be Tempest, and the volume is clearly and beautifully printed, and can be slipped into a coat pocket. Each new volume of this Shakespeare will be a literary event.

$$
\text { A. W. Pollard. }
$$

